\title{
Сильно легированные слои GaAs: Te, полученные в процессе МОГФЭ с использованием диизопропилтеллурида в качестве источника
}

\author{
(c) В.М. Данильцев ${ }^{+}$, Е.В. Демидов ${ }^{+}$, М.Н. Дроздов ${ }^{+*}$, Ю.Н. Дроздов ${ }^{+*}$, С.А. Краев ${ }^{+}$, \\ Е.А. Суровегина ${ }^{+}$, В.И. Шашкин ${ }^{+*}$, П.А. Юнин ${ }^{+*}$
}

\author{
+ Институт физики микроструктур Российской академии наук, \\ 603950 Нижний Новгород, Россия \\ * Нижегородский государственный университет им. Н.И. Лобачевского, \\ 603950 Нижний Новгород, Россия \\ E-mail: drozdyu@ipmras.ru
}

(Получена 27 апреля 2016 г. Принята к печати 10 мая 2016 г.)

\begin{abstract}
Изучены возможности предельно высокого легирования теллуром эпитаксиальных слоев GaAs методом металлоорганической газофазной эпитаксии при использовании диизопропилтеллурида в качестве источника. Показано, что вхождение теллура в GaAs происходит вплоть до концентрации атомов $\sim 10^{21} \mathrm{~cm}^{-3}$ без заметных эффектов диффузии и сегрегации. Хорошие значения концентрации носителей $\left(2 \cdot 10^{19} \mathrm{~cm}^{-3}\right)$ и удельного контактного сопротивления невплавных омических контактов $\left(1.7 \cdot 10^{-6} \mathrm{OM} \cdot \mathrm{cm}^{2}\right)$ дают основания для использования таких слоев для создания невплавных омических контактов в электронных приборах. Обнаружено резкое снижение электрической активности атомов Те, падение подвижности электронов и повышение контактного сопротивления при концентрации атомов выше $2 \cdot 10^{20} \mathrm{~cm}^{-3}$.
\end{abstract}

\section{1. Введение}

Сильно легированные донорной примесью слои $n^{+}$-GaAs необходимы для создания омических контактов невплавного типа в разнообразных приборах микрои оптоэлектроники, таких как диоды и транзисторы с двумерным газом электронов [1]. В отличие от контактов вплавного типа, их создание не требует нагрева готовых структур, не возникают промежуточные, неоднородные по площади слои [2]. Требования к контактам постоянно повышаются вследствие сокращения размера приборов. Если считать приемлемым сопротивление контакта $R=1$ Ом, то контактное сопротивление для контакта с площадью 1 мкм $^{2}$ должно составлять $r_{c}=1 \cdot 10^{-8}$ Ом $\cdot$ см$^{2}$, что пока остается трудно достижимой задачей [1]. Для многих приборов приемлемой является площадка $10 \times 10$ мкм $^{2}$, и $r_{c}=1 \cdot 10^{-6} \mathrm{OM} \cdot \mathrm{cm}^{2}$. $\mathrm{B}$ случае $\mathrm{GaAs}$ для снижения контактного сопротивления используется сильное легирование приповерхностной области, которое обеспечивает туннельное прохождение электронами границы раздела [3]. Одним из лучших вариантов донорного легирования арсенида галлия считается легирование атомами теллура [3-5]. Для получения слоев $\mathrm{GaAs}$ : Те используются различные методы эпитаксии: жидкофазная [6], молекулярно-пучковая с газовыми источниками $[5,7]$ и металлоорганическая газофазная (МОГФЭ) [8,9]. В качестве источника обычно используется диэтилтеллурид (DETe). Альтернативным источником может служить $\left(i-\mathrm{C}_{3} \mathrm{H}_{7}\right)_{2} \mathrm{Te}-$ диизопропилтеллурид (DIPTe), который пока слабо изучен в процессах МОГФЭ, хотя имеет не столь высокое давление паров: 2.11 Topp - DETe; 0.68 Topp — DIPTe при $0^{\circ} \mathrm{C}$. Это важно, поскольку позволяет уменьшать поток водорода через источник Те при разбавлении до нужного уровня легирования. При легировании теллуром сохра- няется ряд нерешенных проблем: шероховатость поверхности [5], сильная зависимость концентрации теллура в слое от скорости роста, ориентации подложки и других параметров процесса эпитаксии [8]. В высоковакуумных установках наблюдается реиспарение Те с поверхности, начиная с температур $\sim 540^{\circ} \mathrm{C}$ [7]. Описано также явление „супердилатации“, „сверхрасширения“ решетки GaAs при легировании Te $[4,10]$, физический смысл которого неочевиден.

В настоящей работе исследована возможность получения высококачественных сильно легированных теллуром эпитаксиальных слоев GaAs в процессе МОГФЭ при использовании DIPTe в качестве источника и изучены свойства невплавных омических контактов к этим слоям.

\section{2. Эксперимент}

Эпитаксиальные слои GaAs:Te выращивались на установке металлоорганической газофазной эпитаксии Epiquip VP-502 RP в системе $\mathrm{Ga}\left(\mathrm{CH}_{3}\right)_{3}-\mathrm{AsH}_{3}-\mathrm{H}_{2}$ при температуре подложки $600-750^{\circ} \mathrm{C}$. Источником легирующей примеси теллура являлся DIPTe $-\left(i-\mathrm{C}_{3} \mathrm{H}_{7}\right)_{2} \mathrm{Te}$. В качестве подложек использовались пластины GaAs, paзориентированные относительно плоскости (100) на $2^{\circ}$ в сторону $\langle 110\rangle$. Для анализа диффузии Те выращивали слои с модуляцией потока Те и $\delta$-слои GaAs:Te.

Концентрация атомов Те в слое определялась методом вторично-ионной масс-спектрометрии (ВИМС, TOF-SIMS 5) с послойным стравливанием. Методом рентгеновской дифракции (РД), дифрактометр Bruker D8 Discover, изучалась деформация решетки GaAs, по которой оценивались концентрации теллура в решетке GaAs на основе закона Вегарда и ковалентных тетраэдрических радиусов атомов [11]. Концентрация и подвижность носителей тока определялись методом эффекта Холла в 
геометрии Ван-дер-Пау. Металлические контакты Ti/Au напылялись методом электронно-лучевого распыления в вакууме на установке Amod-206 при комнатной температуре. Контактное сопротивление измеряли методом линии передачи TLM по зависимости сопротивления от расстояния между контактами. Шероховатость поверхности измеряли на оптическом профилометре Talysurf CCI 2000.

\section{3. Результаты и обсуждение}

Исследовано влияние температуры подложки и потока DIPTe на вхождение атомов Те в слой, $n$ (SIMS), вхождение в решетку кристалла GaAs, $n(\mathrm{XRD})$, концентрацию свободных носителей, $n$ (Hall), слоевое сопротивление, $R_{\mathrm{sh}}$, холовскую подвижность носителей, $\mu$, контактное сопротивление невплавных омических контактов, $r_{c}$.

На рис. 1 показана зависимость концентрации атомов теллура в слое $n$ (SIMS) от потока DIPTe при температуре роста $T_{g}=700^{\circ} \mathrm{C}$. Видно, что вхождение теллура в слой происходит вплоть до $6 \cdot 10^{20} \mathrm{~cm}^{-3}$ и зависимость примерно линейная. Аппроксимация к $n$ (SIMS $)=0$ дает $f(\mathrm{DIPTe}) \neq 0$, что может объясняться реиспарением Те с поверхности при этой температуре. В вакуумных установках реиспарение Те становится заметным, начиная с более низких температур $\sim 540^{\circ} \mathrm{C}$ [7].

Зависимость вхождения Те в слой от температуры (не приводится) показывает, что концентрация Те достигает $\sim 10^{21} \mathrm{~cm}^{-3}$ при $600^{\circ} \mathrm{C}$, но наблюдается значительное уменьшение вхождения теллура с увеличением температуры эпитаксии. Аналогичный эффект наблюдался и другими авторами [5,7]. Эффект объяснялся реиспарением атомов Те с поверхности из-за сильной летучести теллура.

Зависимость вхождения атомов Те в решетку GaAs и концентрации свободных носителей от концентрации атомов Те в слое показана на рис. 2. Видно,

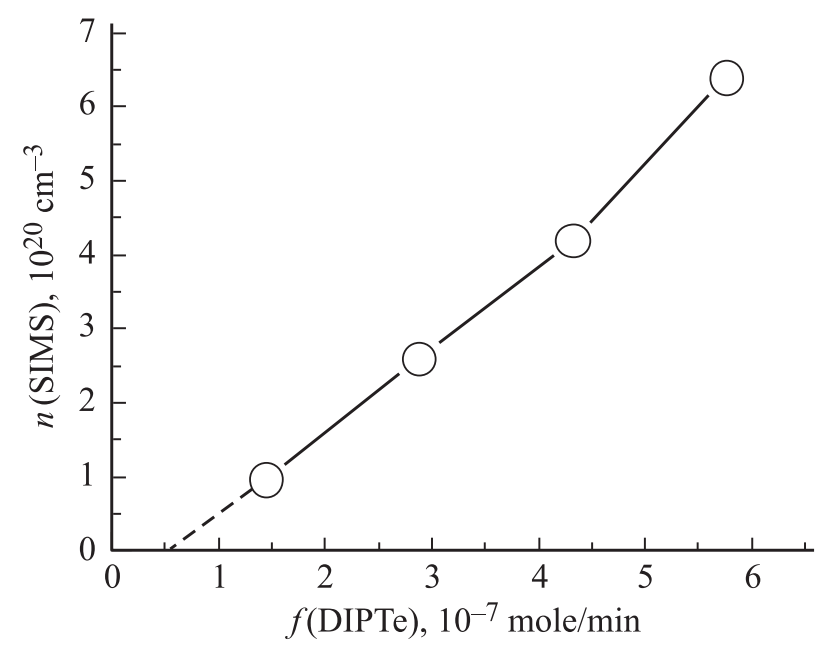

Рис. 1. Зависимость концентрации атомов теллура в слое (метод ВИМC) от потока DIPTe. Температура роста $T_{g}=700^{\circ} \mathrm{C}$.

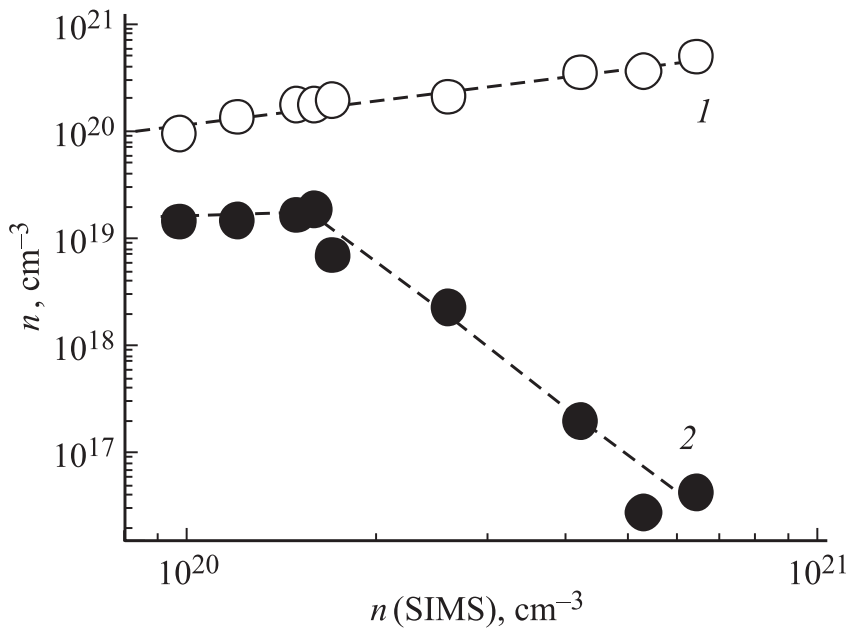

Рис. 2. Связь рентгеновской (1) и холловской (2) концентраций с атомной концентрацией теллура в слое. Включены все образцы независимо от потока DIPTe и температуры роста.

что концентрация свободных носителей начинает резко падать после достижения атомной концентрации $n(\mathrm{SIMS})=1.6 \cdot 10^{20} \mathrm{~cm}^{-3}$. Подобное поведение наблюдалось и при других методах эпитаксиального наращивания слоев $\mathrm{GaAs}: \mathrm{Te}[4,12]$. Это говорит о наличии общей закономерности вхождения атомов Те в GaAs. Характер зависимости $n(\mathrm{XRD})$ от $n(\mathrm{SIMS})$ в этой области концентраций меняется слабо, значит, атомы теллура продолжают входить в решетку GaAs и деформировать ее. По современным представлениям причиной падения суммарной концентрации свободных носителей является компенсация доноров TeAs акцепторными комплексами с включением вакансии галлия $\mathrm{Te}_{\mathrm{As}} \mathrm{V}_{\mathrm{Ga}}[4,12]$.

Если анализировать зависимость деформации решетки не от атомной концентрации, а от концентрации носителей, как это часто делается в литературе, например, [4,10,12], то мы увидим „супердилатацию“, „сверхрасширение“ решетки GaAs, однако на рис. 2 показано, что деформация от вхождения атомов Те в слой зависит почти линейно. Наклон линии даже меньше, чем для полного вхождения атомов Те в решетку. Название „супердилатация“ (superdilation) в данном случае представляется неправильным.

Слоевое сопротивление растет с повышением атомной концентрации теллура в слое (не приводится), что можно связать с увеличением концентрации центров рассеяния носителей, когда их число превышает $10^{20} \mathrm{~cm}^{-3}$.

Исследование методом ВИМС показало, что распределение теллура по глубине слоя однородно, без всплеска на поверхности, что указывает на практическое отсутствие эффекта сегрегации теллура. Примеси Н, С, $\mathrm{O}, \mathrm{S}$ и $\mathrm{Cl}$ даже в сильно легированных теллуром образцах находятся на уровне, соответствующем нелегированному эпитаксиальному GaAs. Использование многократного импульсного легирования GaAs теллуром показало, 


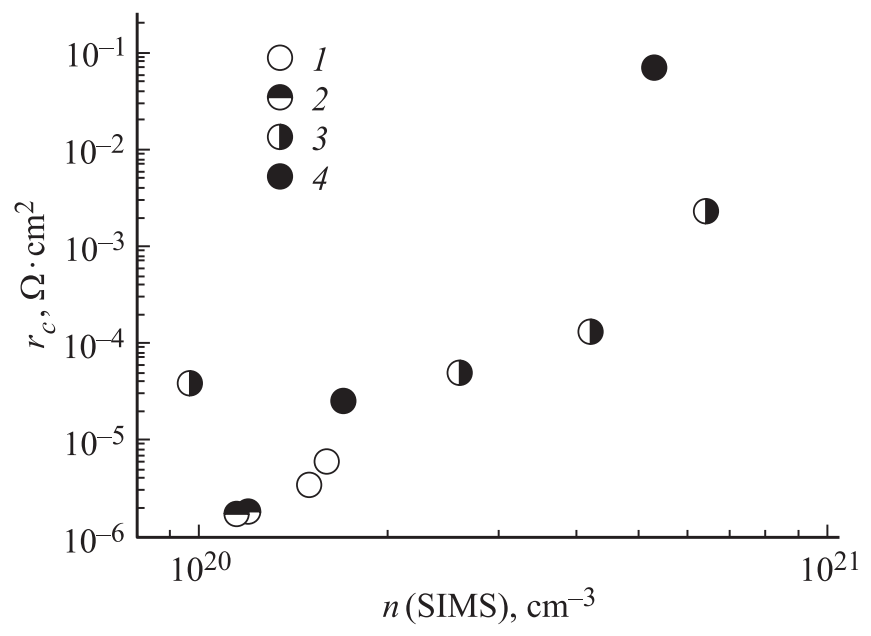

Рис. 3. Удельное контактное сопротивление в зависимости от атомной концентрации Те в слое. Температура роста: $1-600$, $2-650,3-700,4-750^{\circ} \mathrm{C}$.

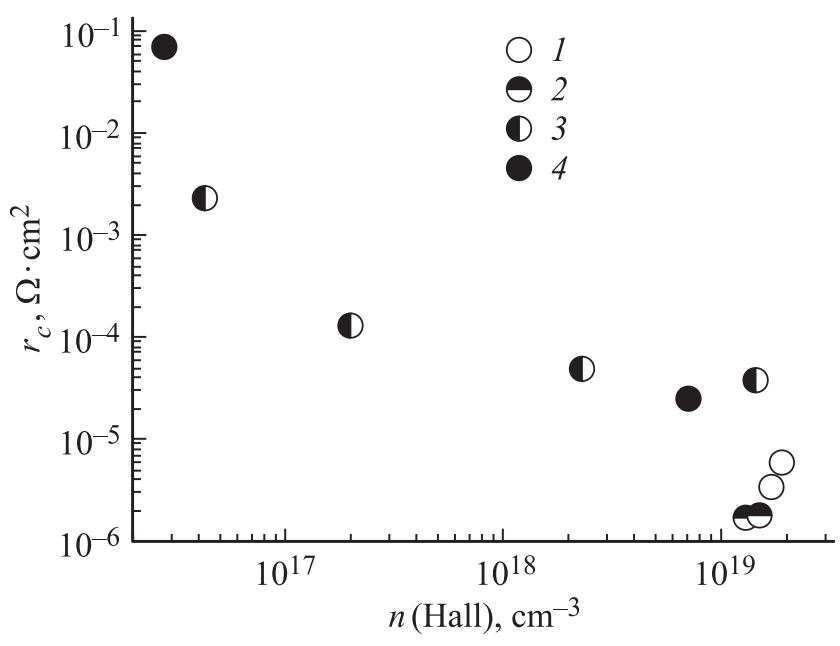

Pис. 4. Удельное контактное сопротивление в зависимости от холловской концентрации свободных носителей в слое. Температура роста: $1-600,2-650,3-700,4-750^{\circ} \mathrm{C}$.

что высота всплесков концентрации теллура на разной глубине в слое сохраняется, что также свидетельствует об отсутствии эффектов сегрегации атомов теллура в арсениде галлия в ходе ростового процесса, в отличие от слоев GaInP:Te [9]. Этот факт подтверждается и малой шириной $\delta$-слоя GaAs:Te, около 5 нм на его полувысоте по данным ВИМС.

На рис. 3 и 4 показано удельное контактное сопротивление в зависимости от атомной и холловской концентрации с разделением точек по температуре роста. Видно, что контактное сопротивление воспроизводимо достигает минимума $r_{c}=1.7 \cdot 10^{-6} \mathrm{OM} \cdot \mathrm{cm}^{2}$ при $T_{g}=650^{\circ} \mathrm{C}$, атомной концентрации $n(\mathrm{SIMS})=1.2 \cdot 10^{20} \mathrm{~cm}^{-3}$ и холловской $n($ Hall $)=1.5 \cdot 10^{19} \mathrm{~cm}^{-3}$. Сильно влияет температура роста, но при фиксированной температуре наблюдается падение $r_{c}$ при увеличении концентрации носителей, либо уменьшении атомной концентрации в области концентраций $n$ (SIMS) от $10^{20}$ до $10^{21} \mathrm{~cm}^{-3}$.

Полученные значения $r_{c}=1.7 \cdot 10^{-6} \mathrm{OM} \cdot \mathrm{cm}^{2}$ вполне приемлемы для некоторых практических приложений и в сравнении с литературными данными по $n$-GaAs уступают только контактам на слоях с очень высокой концентрацией носителей, полученных молекулярнослоевой эпитаксией $[2,13]$. Характерные значения для невплавных омических контактов к $n$-GaAs, судя по обзору [3], составляют $2 \cdot 10^{-6} \mathrm{~cm}^{-3}$ и более. Среднеквадратичная шероховатость поверхности, измеренная методом оптической профилометрии (Talysurf CCI 2000)

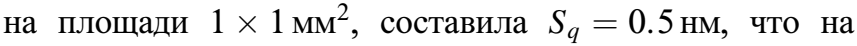
много лучше данных [5] для сопоставимых температур роста, 25 нм при $T_{g}=600^{\circ} \mathrm{C}$.

На рис. 2 и 3 показано, что легирование теллуром GaAs имеет смысл до концентраций $\sim(1-1.5) \cdot 10^{20} \mathrm{~cm}^{-3}$. При больших концентрациях атомов теллура сильно снижается его электрическая активность (рис. 2) и возрастает омическое сопротивление (рис. 3).

\section{4. Заключение}

При использовании диизопропилтеллурида для легирования арсенида галлия в методе МОГФЭ был изучен диапазон концентраций атомов Те в GaAs до $10^{21} \mathrm{~cm}^{-3}$. При концентрациях в области $2 \cdot 10^{20} \mathrm{~cm}^{-3}$ достигается максимум в электрической активности атомов теллура - максимальная холловская концентрация носителей $1.5 \cdot 10^{19} \mathrm{~cm}^{-3}$ и минимальное удельное контактное сопротивление $41.7 \cdot 10^{-6} \mathrm{OM} \cdot \mathrm{cm}^{2}$.

Работа поддержана Министерством образования и науки России, проект RFMEFI60714X0071. Использовано оборудование Центра коллективного пользования „Физика и технология микро- и наноструктур“.

\section{Список литературы}

[1] A.K. Baraskar, M.A. Wistey, V. Jain, U. Singisetti, G. Burek, B.J. Thibeault, Y.J. Lee, A.C. Gossard, M.J.W. Rodwell. J. Vac. Sci. Technol. B, 27, 2036 (2009).

[2] G. Stareev, H. Kunzer, G. Dorfman. J. Appl. Phys., 74, 7344 (1993).

[3] Т.В. Бланк, Ю.А. Гольдберг. ФТП, 41, 1281 (2007)

[4] D.T.J. Hurle. J. Appl. Phys., 107, 121301 (2010).

[5] B. Paquette, B. Ilahi, V. Aimez, R. Arés. J. Cryst. Growth, 383, 30 (2013).

[6] J. Park, P.A. Barnes, M.L. Lovejoy. Appl. Phys. Lett., 67 (7), 968 (1995).

[7] M. Kamp, G. Mörsch, J. Gräber, H. Lüth. J. Appl. Phys., 76, 1974 (1994)

[8] B. Galiana, I. Rey-Stolle, C. Algora, I. García. J. Appl. Phys., 104, 114906 (2008).

[9] I. Garsia, I. Rey-Stolle, B. Galiana, C. Algora. J. Cryst. Growth, 298, 794 (2007). 
[10] J.B. Mullin, B.W. Straughan, C.M.H. Driscoll, A.F.W. Wi1loughby. J. Appl. Phys., 47, 2584 (1976).

[11] Современная кристаллография. T. 2. Структура кристаллов / Б.К. Вайнштейн, В.М. Фридкин, В.Л. Инденбом (М., Наука, 1979).

[12] D.T.J. Hurle. J. Appl. Phys., 85, 6957 (1999).

[13] Y. Oyama, P. Plotka, F. Matsumoto, T. Kurabayashi, T. Hamano, H. Kikuchi, J. Nishizawa. J. Electrochem. Soc., 146 (1), 131 (1999).

Редактор Г.А. Оганесян

\title{
Heavily doped GaAs: Te layers, obtained in the MOVPE process using diizopropiltellurid as a source
}

\author{
V.M. Daniltsev ${ }^{+}$, E.V. Demidov ${ }^{+}$, M.N. Drozdov ${ }^{+*}$, \\ Yu.N. Drozdov ${ }^{+*}$, E.A. Surovegina ${ }^{+}$, S.A. Kraev ${ }^{+}$, \\ V.I. Shashkin ${ }^{+*}$, P.A. Yunin ${ }^{+*}$ \\ + Institute for Physics of Microstructures, \\ Russian Academy of Sciences, \\ 603950 Nizhny Novgorod, Russia \\ * Lobachevsky State University of Nizhny Novgorod, \\ 603950 Nizhny Novgorod, Russia
}

Abstract The possibilities of extremely heavy doping of epitaxial GaAs layers by tellurium atoms with metal organic vapor phase epitaxy using diizopropiltellurid source was investigated. It is shown that incorporation of tellurium atoms in GaAs layer takes place for concentrations up to about $10^{21} \mathrm{~cm}^{-3}$ without noticeable effects of the diffusion and segregation. Good value of the carrier density $\left(2 \cdot 10^{19} \mathrm{~cm}^{-3}\right)$ and the specific contact resistance of ohmic contacts $\left(1.7 \cdot 10^{-6} \Omega \cdot \mathrm{cm}^{2}\right)$ provide a basis for the use of such layers to create non-alloyed ohmic contacts in electronic devices. A sharp decline in the electrical activity of Te atoms, the fall of the electron mobility and increase the contact resistance was observed for a concentration higher than $2 \cdot 10^{20} \mathrm{~cm}^{-3}$. 